\title{
Deformation in cemented mudrock (Callovo-Oxfordian Clay) by microcracking, granular flow and phyllosilicate plasticity: insights from triaxial deformation, broad ion beam polishing and scanning electron microscopy
}

\author{
Guillaume Desbois $^{1}$, Nadine Höhne ${ }^{1}$, Janos L. Urai ${ }^{1}$, Pierre Bésuelle ${ }^{2}$, and Gioacchino Viggiani ${ }^{2}$ \\ ${ }^{1}$ Structural Geology, Tectonics and Geomechanics, RWTH Aachen University, Lochnerstrasse 4-20, 52056 Aachen, Germany \\ ${ }^{2}$ Univ. Grenoble Alpes, CNRS, Grenoble INP, 3SR, 1270 Rue de la Piscine, 38610 Gières, France \\ Correspondence to: Guillaume Desbois (guillaume.desbois@emr.rwth-aachen.de)
}

Received: 12 September 2016 - Discussion started: 4 October 2016

Revised: 8 February 2017 - Accepted: 17 February 2017 - Published: 9 March 2017

\begin{abstract}
The macroscopic description of deformation and fluid flow in mudrocks can be improved by a better understanding of microphysical deformation mechanisms. Here we use a combination of scanning electron microscopy (SEM) and broad ion beam (BIB) polishing to study the evolution of microstructure in samples of triaxially deformed Callovo-Oxfordian Clay. Digital image correlation (DIC) was used to measure strain field in the samples and as a guide to select regions of interest in the sample for BIB-SEM analysis. Microstructures show evidence for dominantly cataclastic and minor crystal plastic mechanisms (intergranular, transgranular, intragranular cracking, grain rotation, clay particle bending) down to the nanometre scale. At low strain, the dilatant fabric contains individually recognisable open fractures, while at high strain the reworked clay gouge also contains broken non-clay grains and smaller pores than the undeformed material, resealing the initial fracture porosity.
\end{abstract}

\section{Introduction}

Mudrocks constitute up to $80 \%$ of the Earth's sedimentary rocks (Stow, 1981). Due to their low permeability and selfsealing properties (Boisson, 2005; Bernier et al., 2007), claystones are considered for nuclear waste disposal and seals for storage in deep geological formations (Salters and Verhoef, 1980; Shapira, 1989; Neerdael and Booyazis, 1997; Bonin, 1998; Ingram and Urai, 1999; ONDRAF/NIRAS, 2001; NA-
GRA, 2002; NEA, 2004; ANDRA 2005; IAEA, 2008). Predictions of mechanical and transport properties over long timescales are essential for the evaluation of subsurface integrity. For this, it is generally agreed that a multiscale experimental approach that combines measurement of bulk mechanical and transport properties with microstructural study to identify deformation mechanisms is required to develop microphysics-based constitutive equations, which can be extrapolated to timescales not available in the laboratory, after comparison with naturally deformed specimens (Morgenstern and Tchalenko, 1967; Tchalenko, 1968; Lupini et al., 1981; Rutter et al., 1986; Logan et al., 1979, 1987, 1992; Marone and Scholz, 1989; Evans and Wong, 1992; Katz and Reches, 2004; Niemeijer and Spiers, 2006; Colletini et al., 2009; Haines et al., 2009, 2013; French et al., 2015; Crider, 2015; Ishi, 2016).

In the field of rock mechanics and rock engineering, experiments are performed to low strain and over a relatively short time in order to predict damage and deformation in tunnelling and mining, for example. Here, a macroscopic and phenomenological approach is common to characterise mechanical and transport properties and to establish the constitutive laws. Microstructures are rarely studied because the strained regions are difficult to find (except for macroscopic fractures) and because microstructures below micrometre scales are elusive. However, it is well established that for long-term predictions a microphysics-based understanding of mechanical and fluid flow properties in mudrocks provides a better basis for extrapolating constitutive equations beyond 
the timescales accessible in the laboratory. This requires integration of measurement of the mechanical and transport properties with microstructures in order to obtain a multiscale description of deformation in mudrocks at low strain.

The microstructural geology community studied microstructures in deformed mudrocks to infer deformation mechanisms (Dehandschutter et al., 2004; Gratier et al., 2004; Klinkenberg et al; 2009; Renard, 2012; Robinet et al., 2012; Richard et al., 2015; Kaufhold et al., 2016), but this was limited by problems with sample preparation for highresolution electron microscopy. Conversely, the mechanical properties and related microstructures of natural and experimental high-strain fault rocks have been studied extensively (Bos and Spiers, 2001; Faulkner et al., 2003; Marone and Scholz, 1989). For Opalinus Clay (OPA) deformed in laboratory, Nüesch (1991) and Jordan and Nüesch (1989) concluded that cataclastic flow was the main deformation mechanism, with kinking and shearing on $R$ and $P$ surfaces at the micro-scale; however, this was only based on observations with optical microscopy, so that grain-scale processes were not resolved. Klinkerberg et al. (2009) demonstrated a correlation between compressive strength and carbonate content of two claystones; this correlation is positive for OPA but negative for Callovo-Oxfordian Clay (COX). This was explained by the differences in grain size, shape, and spatial distribution of the carbonate (Klinkerberg et al., 2009; Bauer-Plaindoux et al., 1998). Microstructural investigations using BIB-SEM (broad ion beam and scanning electron microscopy) and FIB-TEM (focussed ion beam and transmitted electron microscopy) milling tools in OPA from the main fault in the Mont Terri underground research laboratory (Laurich et al., 2014, 2017) showed that inter- and transgranular microcracking, pressure solution, clay neoformation, phyllosilicate crystal plasticity and grain boundary sliding all play an important role during the early stages of faulting in OPA. However, simple cataclastic microstructures are rare due to the high shear strain and there was an almost complete loss of porosity in micro-shear zones.

Digital image correlation (DIC) applied to images acquired during experimental deformation provides a method to directly measure the local displacement fields (in 2-D or 3 -D depending on the imaging method) and locally quantifies strain over time (Lenoir et al., 2007 (claystone, 3-D, X-ray tomography); Bornert et al., 2010 (claystone, 2-D, optical microscopy); Bésuelle and Hall, 2011 (claystone, 2-D, optical microscopy); Dautriat et al., 2011 (carbonates, 2-D, optical microscopy and SEM); Wang et al., 2013, 2015 (claystone, 2-D, environmental SEM); Fauchille et al., 2015 (claystone, 2-D, optical microscopy); Sone et al., 2015 (shale, 2D, SEM)). For samples with grain sizes above micrometres, this approach allows the study of processes that occur at grain scale with high resolution (Hall et al., 2010 (sand, 3-D, X-ray tomography); Andò et al., 2012 (sand, 3-D, X-ray tomography); Bourcier et al., 2012, 2013 (rock salt, 2-D, optical microscopy and environmental SEM); Wang et al., 2015 (clay- stone, 2-D, environmental SEM)). On claystones, DIC was used to study swelling in environmental SEM (Wang et al., 2013, 2015) to measure strain between the clay matrix and non-clay minerals.

Microstructural studies in naturally compacted mudrocks are currently in rapid development, enabled by the development of ion beam milling tools (e.g. FIB and BIB), which allow imaging of mineral fabrics and porosity down to the nanometre scale in very high-quality cross sections with SEM and TEM (Lee et al., 2003; Desbois et al., 2009, 2011, 2013, 2016; Loucks et al., 2009; Curtis et al., 2010; Heath et al., 2011; Klaver et al., 2012; Keller et al., 2011, 2013; Houben et al., 2013, 2014; Hemes et al., 2013, 2015; Laurich et al., 2014; Warr et al., 2014; Song et al., 2016). Serial sectioning allows the reconstruction of microstructure in 3-D (Keller et al., 2011, 2013; Milliken et al., 2013; Hemes et al., 2015), and cryogenic techniques can image the pore fluid in the samples and avoid artefacts produced by drying (Desbois et al., 2013, 2014; Schmatz et al., 2015).

Previous work has shown that the mechanical properties of COX do not only depend on the fraction and mineralogy of the clay but also on water content and texture (BauerPlaindoux et al., 1998). Chiarelli et al. (2000) showed that COX is more brittle with increasing calcite content and more ductile with increasing clay content, and they proposed two deformation mechanisms: plasticity induced by slip of clay sheets and induced anisotropic damage as indicated by microcracks at the interface between grains and matrix; however, they provided little microstructural evidence to support this. Gasc-Barbier et al. (2004), Fabre and Pellet (2006), Chiarelli et al. (2003) and Fouché et al. (2004) reported that the COX has an unconfined compressive strength of 20 to $30 \mathrm{MPa}$ and a Young's modulus of 2 to $5 \mathrm{GPa}$. In the context of underground storage of radioactive waste, these papers try to predict the mechanical evolution of COX over the period of thousands of years. The effects studied included creep, pore-pressure dissipation, swelling, contraction, chemical effects, pressure solution and force of crystallisation. Although these papers develop elaborate constitutive laws, they provide very limited microstructural observations. The need for micromechanical observations was already recognised by Yang et al. (2012) and Wang et al. (2013, 2015). From DIC applied to optical and environmental scanning electron microscope (ESEM) images, these authors showed how heterogeneous strain fields correlate with microstructure and recognised shear bands and tensile microcracks.

For highly overconsolidated claystones from the Variscan foreland thrust belt in the Ardennes and Eifel, Holland et al. (2006) proposed an evolutionary model starting with mechanical fragmentation of the original fabric. In this model, the initial loss of cohesion is driven by kinking, folding and microfracturing processes, with an increasing porosity and permeability. Abrasion during progressive deformation increases the amount of clay gouge, and resealing occurs by decrease in pore size of the clay gouge. 


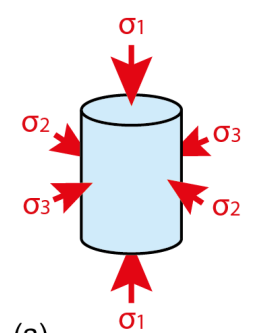

(a)

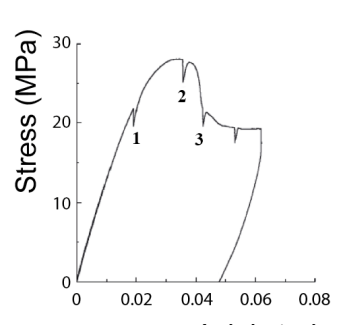

Axial strain

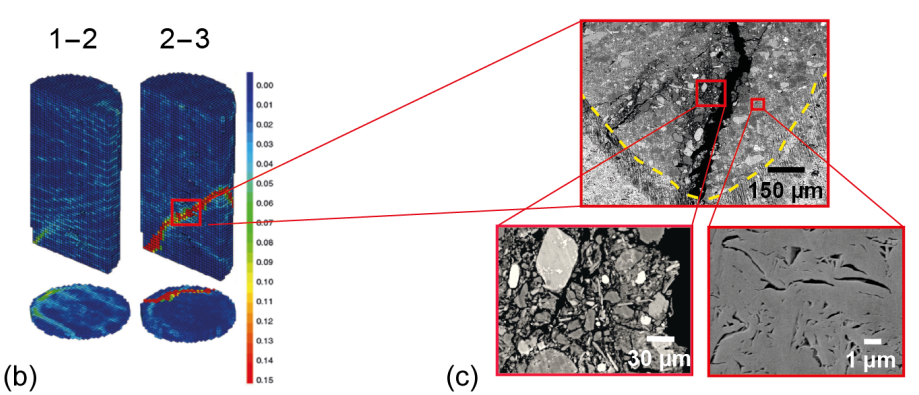

(c)

Bulk

Figure 1. Drawing of the experimental concept used for the investigation of experimentally deformed fine-grained mudrocks from bulk scale to nanometre scale. The example is based on (a) a triaxial deformation test (10 MPa confining pressure) performed on a cylindrical Callovo-Oxfordian Clay, (b) volumetric DIC on X-ray microtomography images to follow displacement fields (after Lenoir et al., 2007), and (c) SEM imaging on high-quality cross sections prepared by BIB. (a) Steps when X-ray microtomography images were acquired are indicated by 1, 2 and 3. (b) Deformation increments between steps 1 and 2 and steps 2 and 3 are indicated by 1-2 and 2-3 respectively.

In summary, deformation mechanisms in mudrocks are poorly understood, especially at low strain. Although as a first approximation the plasticity of cemented and uncemented mudrocks can be described by effective pressuredependent constitutive models, the full description of their complex deformation and transport properties would be much improved by better understanding of the microscale deformation mechanisms. There is a wide range of possible mechanisms: intra- and intergranular fracturing, cataclasis, grain boundary sliding, grain rotation and granular flow, plasticity of phyllosilicates, and the poorly known plasticity of nanoclay aggregates with the strong role of clay-bound water, cementation, fracture sealing and solution precipitation.

This contribution combines stress-strain data and measurement of displacement fields by DIC with microstructural investigations in areas selected based on the DIC results. For this, we prepared millimetre-sized high quality cross sections by (BIB) milling followed by SEM to infer microphysical processes of deformation with submicron resolution (Fig. 1). The two samples used are from the COX (a cemented claystone): one deformed in plane strain compression at $2 \mathrm{MPa}$ confining pressure (COX-2MPa; Bésuelle and Hall, 2011) and another in triaxial compression at $10 \mathrm{MPa}$ confining pressure (COX-10MPa; Lenoir et al., 2007). Specimens were taken from the Bure site in Meuse-Haute Marne in France and belong to the clay-rich facies of the COX.

\section{Material studied and DIC-derived strain fields}

Triaxial experiments were performed on two COX samples collected at the ANDRA Underground Research Laboratory located at Bure (Meuse-Haute Marne, eastern France) at approximately $550 \mathrm{~m}$ below ground surface (Boisson, 2005). The clay fraction (illite-smectite, illite, chlorite) is $40-45 \%$, carbonate (mostly calcite) and quartz are 25-35 and 30\% respectively and the samples contain minor feldspar, mica and pyrite (Gaucher et al., 2004).

The details of these experiments, including instrumentation, boundary conditions and DIC interpretations are comprehensively described in Bésuelle and Hall (2011) and Lenoir et al. (2007). This contribution mostly presents the microstructural analysis performed on these previously deformed two samples.

The first sample considered in this study (COX-2MPa, sample reference: EST32896) was tested in plane strain compression at $2 \mathrm{MPa}$ confining pressure. Two-dimensional DIC was performed on consecutive photographs of one side of the specimen (in the plane of deformation) throughout the test. Further details are given in Bésuelle and Hall (2011). The second sample (COX-10MPa) was tested in triaxial compression at $10 \mathrm{MPa}$ confining pressure. Three-dimensional DIC was performed on consecutive X-ray images of the specimen obtained in a synchrotron throughout the test. Further details are given in Lenoir et al. (2007). Please note that in this publication this sample is referred to as ESTSYN01 with drilling reference EST261.

In the following paragraphs, the relevant findings in Bésuelle and Hall (2011) and Lenoir et al. (2007) are summarised.

The prismatic sample COX-2MPa was tested in plane strain compression in a true triaxial apparatus at a constant value of $\sigma_{3}=2 \mathrm{MPa}$. The size of the specimen is $50 \mathrm{~mm}$ in the vertical direction, which is the direction of major principal stress $\left(\sigma_{1}\right), 30 \mathrm{~mm}$ in the direction of intermediate principal stress $\left(\sigma_{2}\right)$, and $25 \mathrm{~mm}$ in the direction of minor principal stress $\left(\sigma_{3}\right)$. The test was displacement controlled, with a constant rate of displacement (in direction 1) of $1.25 \mu \mathrm{m} \mathrm{s}^{-1}$, i.e. a strain rate of $2.5 \times 10^{-5} \mathrm{~s}^{-1}$ (see Bésuelle and Hall, 2011 for further details). Figure 2a shows the evolution of the dif- 


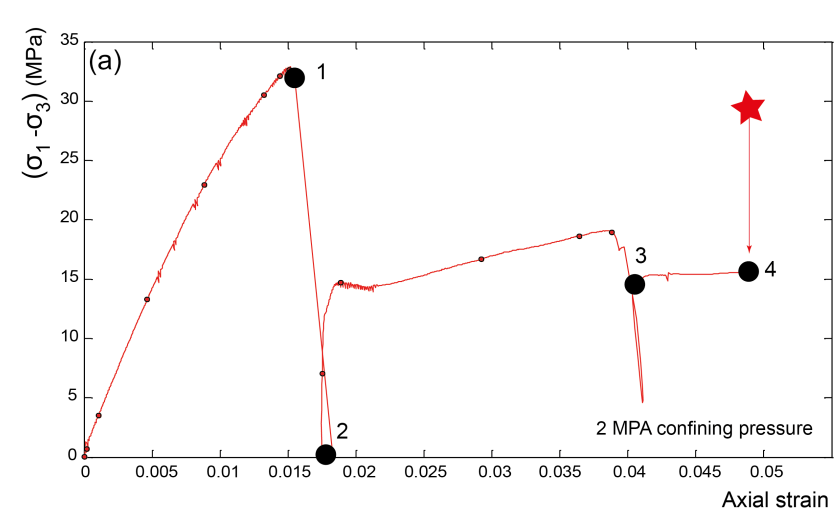

(b)
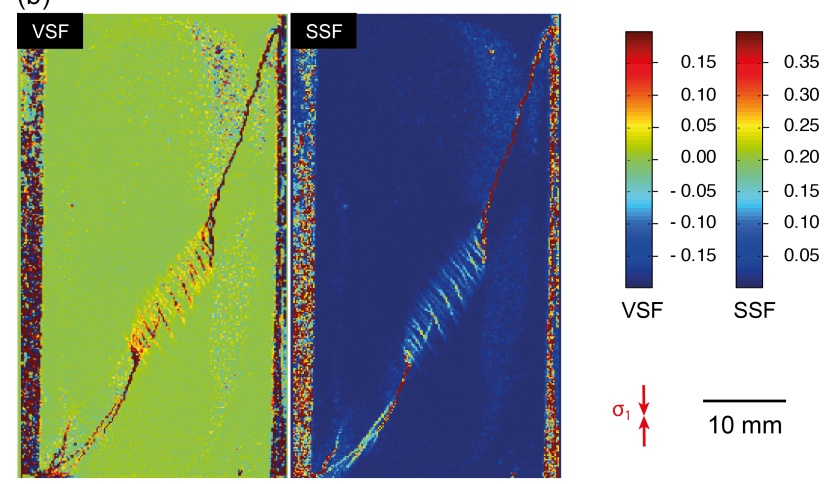

(c)

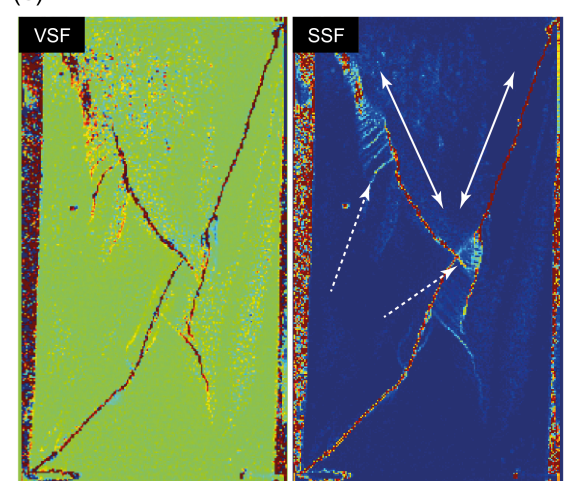

(d)

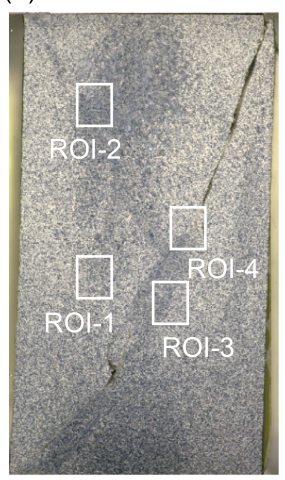

Figure 2. Results of deformation test done on sample COX-2MPa. (a) Deviator stress vs. axial strain response. The red star indicates the state of the sample when BIB-SEM microstructural analyses are done. (b, c) Incremental volumetric strain fields (VSF) and maximum shear strain fields (SSF) for deformation increments 1-2 (b) and 3-4 (c) indicated in (a) after DIC. Arrows with solid lines indicate the set of two conjugated synthetic fractures, whereas the arrows with dashed lines show antithetic fractures oblique to the conjugated fractures. (d) Selection of differently strained areas (region of interest (ROI)) highlighted from DIC analysis for BIB-SEM microstructural analyses. Four ROI were analysed: three at conjugate synthetic fractures in areas with a different amount of diffuse strain and antithetic fractures (ROI-2, ROI-3 and ROI-4) and one in a region without measurable strain (ROI-1). The bedding is perpendicular to the mean principal stress $\sigma_{1}$. Performed according to Bésuelle et al. (2011).

ferential stress $\left(\sigma_{1}-\sigma_{3}\right)$ vs. axial strain. The curve shows a first stress peak at 0.02 axial strain, followed by a strong stress drop. Then, a slow stress increase is observed, followed by a second stress drop at 0.42 axial strain. Afterwards, the stress is quite constant. As shown in Fig. $2 \mathrm{~b}$ and c (gage length of $180 \mu \mathrm{m}$ ), these two stress drops are associated with major faulting in the specimen. The crack that appeared during the second drop is conjugate to the first crack set, which appeared at the first drop. This set of conjugate fractures, at an angle of 20 to $45^{\circ}$ about direction 1, will be referred to as "main synthetic fractures" in the following sections. The DIC-derived strain fields in Fig. $2 \mathrm{~b}$ and c also show that the development of each single conjugate fracture is accompanied by relay zones with a set of antithetic fractures. Moreover, the fracture appearing during the second stress drop (Fig. 2c) also reactivates the first fracture and its associated antithetic fractures. At this resolution (pixel size is $10 \times 10 \mu \mathrm{m}^{2}$ ), the set of conjugate fractures and the associated antithetic fractures are the major features of localised deformation: they represent zones where the sample was sheared, with damaged zones having a thickness of about $60 \mu \mathrm{m}$. Dilatancy was also measured in the damaged zones mentioned above (see volumetric strain fields, Fig. $2 b$ and c).

The cylindrical sample COX-10MPa $(10 \mathrm{~mm}$ in diameter and $20 \mathrm{~mm}$ in height) was deformed in triaxial compression at a confining pressure of $10 \mathrm{MPa}$. The test was carried out under tomographic monitoring at the European Synchrotron Radiation Facility (ESRF) in Grenoble, France, using an original experimental set-up developed at Laboratoire 3SR at the University of Grenoble Alpes (France). Complete 3-D images of the specimens were recorded throughout the test using X-ray microtomography (voxel size was $14 \times 14 \times 14 \mu^{3}$ ). The test was displacement controlled, with a displacement rate of $0.05 \mu \mathrm{m} \mathrm{s}^{-1}$, i.e. an axial strain rate of $2.5 \times 10^{-6} \mathrm{~s}^{-1}$. The stress-strain curve (Fig. 3a) shows only one stress peak at an axial strain of 0.04 . The peak stress is followed by a major stress drop corresponding to the formation of a shear fracture (referred to as main synthetic fracture in the following sections) oriented at an angle of $30-40^{\circ}$ about the direction of the principal stress $\sigma_{1}$ (the DIC-based maximum shear strain fields are given in Fig. $3 \mathrm{~b}$, gage length of $280 \mu \mathrm{m}$ ). The DIC-derived volumetric strain fields (not shown here; see Lenoir et al., 2007) indicate that the shear fracture is accompanied by some slight dilatancy.

\section{Methods: BIB-SEM imaging of deformed microstructures}

After the experiments of Lenoir et al. (2007) and Bésuelle and Hall (2011), deformed samples were stored at low vacuum and room temperature in a desiccator, where they dried slowly. From these deformed samples, subsamples were selected to represent areas with different strain history based on the DIC analysis. For COX-2MPa, three BIB cross sections 

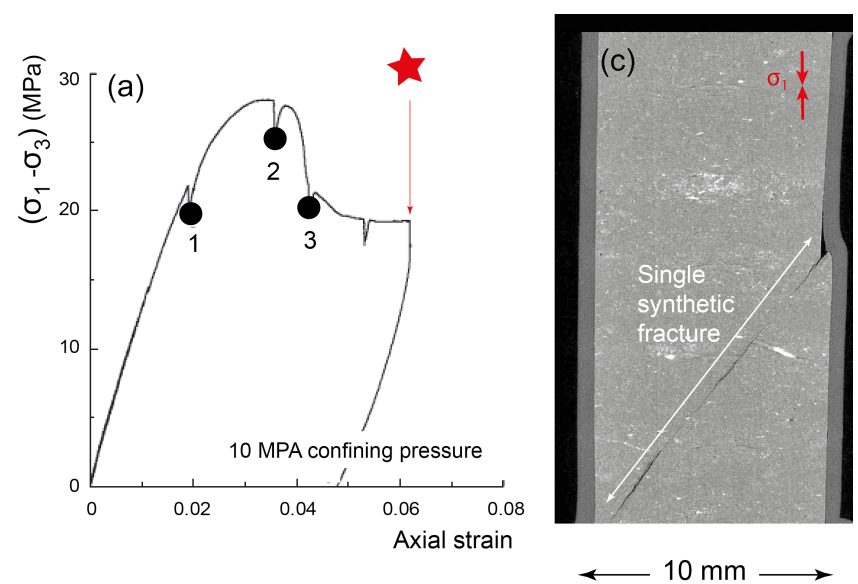

(b)

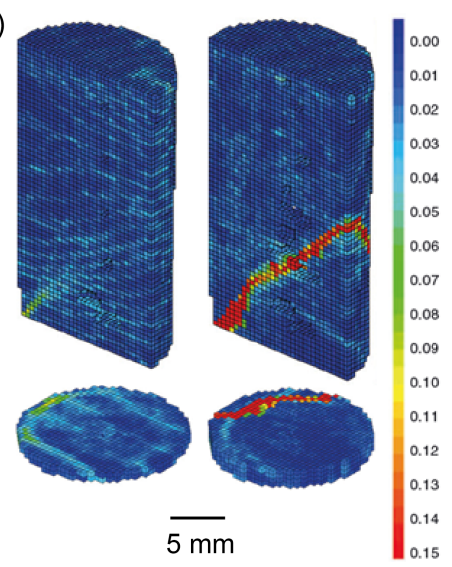

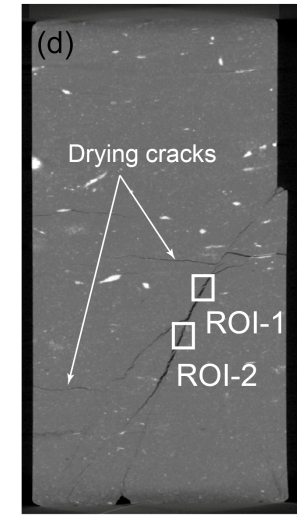

Figure 3. Results of deformation test done on sample COX-10MPa. (a) Deviator stress vs. axial strain response. The red star indicates the state of sample when BIB-SEM microstructural analyses are done. (b) Incremental maximum shear strain fields for deformation increments 1-2 and 2-3 indicated in (a) interpreted after DIC. (c) Shows the X-ray radiography of the sample taken directly at the end of the deformation test, whereas (d) shows the X-ray radiography of the same sample but taken about 10 years after the end of the deformation: drying cracks developed following the bedding, and the aperture of the single shear fracture became larger. (d) Also indicates that two ROI were analysed, both around the single synthetic shear fracture. In (c) and (d) the bedding is perpendicular to the principal stress $\sigma_{1}$ indicated in (c). Performed according to Lenoir et al. (2007).

were prepared around the conjugate fractures in areas with different amounts of diffuse strain (at the resolution of DIC) and antithetic fractures (ROI-2, ROI-3 and ROI-4; Figs. 2d, $5 \mathrm{~b}, \mathrm{c}, \mathrm{d}$ and 6 ) and a fourth BIB cross section is from a region without measurable strain (ROI-1; Figs. 2d and 5a). For COX-10MPa, two BIB-SEM analyses were done around the single shear fracture (Figs. 3d and 5e, f).

Subsamples were first embedded in epoxy, extracted with a low speed diamond saw in dry conditions, pre-polished dry using SiC papers (down to P4000 grade) and BIB polished in a JEOL SM-09010 cross section polisher (for $8 \mathrm{~h}, 1.10^{-3}$

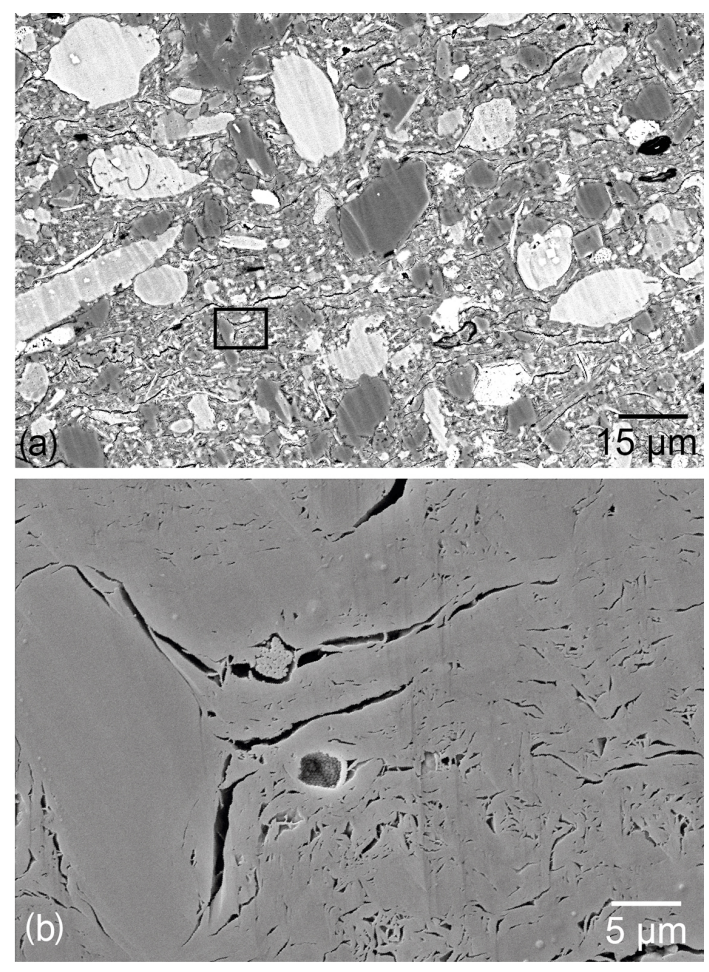

Figure 4. (a) BSE-SEM micrograph of the typical mineral fabric in undeformed COX. (b) SE2 SEM micrograph of a detail indicated by the black box in (a) showing the typical pore fabric in undeformed COX. In both micrographs, the bedding is horizontal.

$1.10^{-4} \mathrm{~Pa}, 6 \mathrm{kV}, 150 \mu \mathrm{A}$ ) to remove a $100 \mu \mathrm{m}$ thick layer of material interpreted to be the layer of damage after polishing with $\mathrm{SiC}$ papers. BIB cross sections were all prepared parallel to the $\sigma_{1}$ and direction and perpendicular to the shear fracture. The BIB cross sections of about $1.5 \mathrm{~mm}^{2}$ (Figs. 5 and 6) were imaged with a Supra 55-Zeiss SEM (SE2 and BSE detectors at $20 \mathrm{kV}$ and working distance $(\mathrm{WD})=8 \mathrm{~mm})$. Further details of the method are given in Klaver et al., 2012, 2015; Houben et al., 2013, 2014; Hemes et al., 2013, 2015; and Desbois et al., 2016.

\section{Results}

\subsection{Overview of microstructures}

The subsample without measurable strain (i.e. ROI-1_COX$2 \mathrm{MPa}$, Fig. 5a) shows non-clay minerals in a clay matrix with a weak-shape-preferred orientation parallel to bedding (perpendicular to the experimental $\sigma_{1}$ ). The clay matrix contains submicron pores typical of compaction and diagenesis, with a power law distribution of pore sizes. Pores commonly have very high aspect ratio, with the long axis oriented subparallel to the bedding. Mineral fabric is very similar to those in the undeformed COX sample (Fig. 4; see Robinet et al., 2012). 

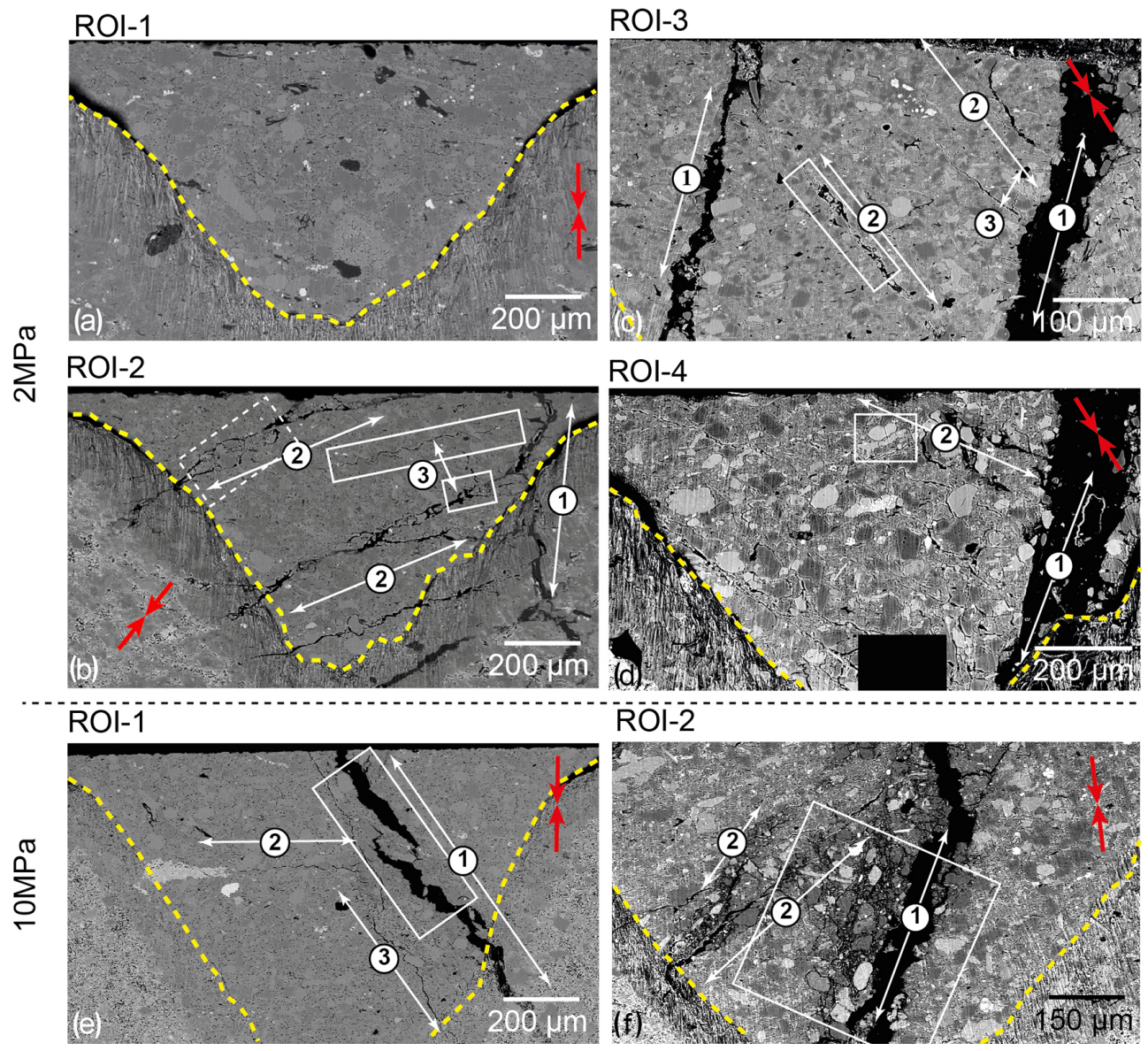

Röí-2

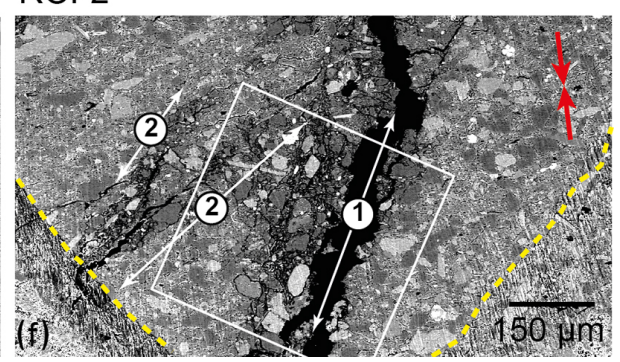

Figure 5. BSE-SEM micrographs of the BIB cross section overviews of COX-2MPa (a-d) and COX-10MPa (e-f) at differently strained areas (ROI) highlighted from DIC analysis in Figs. 2 and 3. Highly strained ROI (b-f) display damaged microstructures where three different types of fracture are identified: (1) the main synthetic fracture, (2) antithetic fractures oriented about $60^{\circ}$ to the main fracture and (3) joints subparallel to the main synthetic fracture. These fractures are respectively indicated by numbers 1, 2 and 3 in the figure. In (b) the white box in dashed lines refers to Fig. 7f; the upper white box in solid lines refers to Fig. 7a and the lower white box in solid lines refers to Fig. 7e. In (c) the white box in solid lines refers to Fig. $7 \mathrm{~g}$. In (d) the white box in solid lines refers to Fig. 7c. In (e) the white box in solid lines refers to Fig. 9. In (c) the white box in solid lines refers to Fig. 11. In all micrographs, the orientation of the principal stress $\left(\sigma_{1}\right)$ is indicated by red arrows. The bedding is perpendicular to $\sigma_{1}$. Dashed yellow lines indicate the boundaries of the BIB-polished areas.

In all other BIB cross sections (Figs. 5c-f and 6), both samples show damaged microstructures. At the sample scale, three different types of fracture are identified: (i) the main synthetic fracture (Sect. 2), (ii) antithetic fractures (Fig. 5) and (iii) joints subparallel to the main fracture. The material between the fracture zones has very similar microstructure to undeformed COX.

\subsection{Detailed description of microstructures}

\subsubsection{Arrays of antithetic fractures}

In COX-2MPa, the antithetic fractures (Fig. 6) are of two different types. Type I is located only in the clay matrix (Fig. 7a), with apertures up to a few micrometres, with boundaries closely matching, suggesting that these are opening mode fractures (Mode I). Type II fractures consist of a damage zone with a thickness of up to $25 \mu \mathrm{m}$ (Fig. 7e, f, g, $\mathrm{h}, \mathrm{i})$, containing angular fragments of non-clay minerals and clay aggregates (Fig. 7h), sometimes with preferred orientation parallel to the fracture. The transition between the damage zone and the undeformed host rock is sharp (Fig. 7f, g, $\mathrm{h}$, i). In relay zones the fracturing becomes so intense that the clay matrix is fragmented into submicron-size fragments (Fig. 7i). Porosity in these relay zones is locally much higher and pores are much larger than in undeformed COX. Fracture boundaries usually do not match (Fig. 7h). Figure 7e shows examples where parts of broken non-clay minerals can be matched.

In COX-10MPa, we observed the two types of antithetic fractures mentioned above. Antithetic fractures of Type I are very similar (indicated in Fig. 5f) to those in COX-2MPa but they are rare, whereas antithetic fractures of Type II contain a 


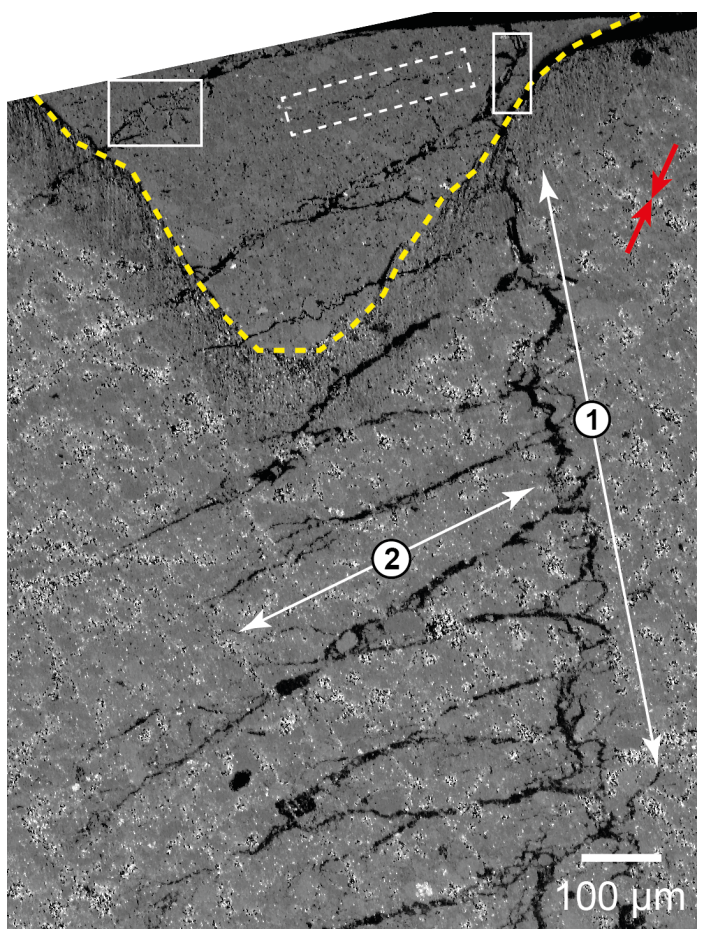

Figure 6. Larger field of BSE-SEM micrograph of the BIB cross section overview at ROI-1 in COX-2MPa sample. It shows the network of antithetic fractures (indicated by number 1 ) oblique to the principle main synthetic fracture (indicated by number 2). The left white box in solid lines refers to Fig. 7f; the white box in dashed lines refers to Fig. $7 \mathrm{a}$ and the right white box in solid lines refers to Fig. 8. Orientation of the principal stress $\left(\sigma_{1}\right)$ is indicated by red arrows. The bedding is perpendicular to $\sigma_{1}$. Dashed yellow lines indicate the boundaries of the BIB-polished areas.

wider damage zone in comparison to those in COX-2MPa, in which the average grain size and the pore size is significantly smaller, consistent with stronger cataclasis at high confining pressure. In parts of the damage zones interpreted to be restraining sections, pores in the reworked clay aggregates cannot be resolved in the SEM.

In both samples, the fragments between the arrays of antithetic fractures show only minor deformation indicated by fractured grains of organic matter (Fig. 7b), calcite (Fig. 7d, c) or quartz (Fig. 7d). Visible relative rotation of parts of fractured grain is rare (Fig. 7d).

\subsubsection{Synthetic fractures}

The synthetic fractures are the regions that localised most of the strain and have the thickest damage zone (Figs. 2 and 3). Here, COX-2MPa and COX-10MPa show very similar microstructures. The grain (fragment) size of non-clay minerals is significantly smaller than in the host rock and their sizes are poorly sorted. In comparison to undeformed samples (Fig. 4a), non-clay minerals also have dominant angular and/or chipped edges (Figs. 8, 9 and 11). Locally, grains
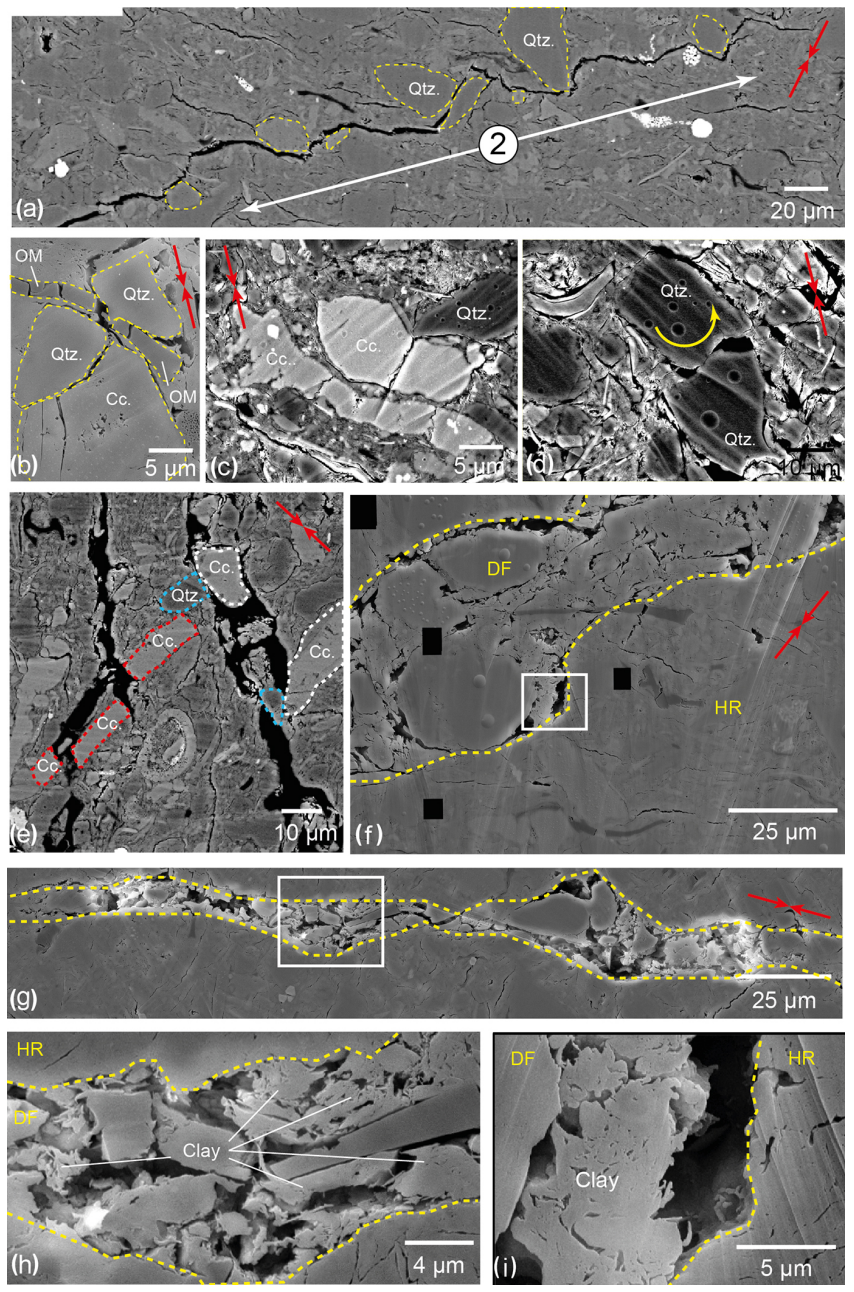

Figure 7. Detailed microstructures in sample COX-2MPa. (a) A fracture running parallel to the antithetic fractures and at the interfaces between non-clay mineral and clay matrix. In (b) intragranular fractures are in calcite grain $(\mathrm{Cc}$.) and transgranular fractures are in organic matter $(\mathrm{OM})$, whereas in (c) transgranular fractures are in Cc. at impingement with quartz grain (Qtz.). (d) A broken quartz grain showing evidence for rotation of its broken fragments. (e) Incipient of flow of broken non-clay minerals within the antithetic fractures indicated by red (Cc.), blue (Qtz.) and white (Cc.) dashed lines. (f) and (g) show parts of antithetic fractures displaying thick damaged fabrics made of broken grains and clay matrix fragments. (h) Details of the white box indicated in (g). (i) Details of the white box indicated in (f), showing the denser and deformed fabric of a part of the clay matrix squeezed between a quartz grain located in the damaged fabric and the boundary with the host rock. In (f)-(i), the damaged fabric is related to a higher porosity in comparison to the host rock. In all micrographs, the orientation of the principal stress $\left(\sigma_{1}\right)$ is indicated by red arrows. The bedding is perpendicular to $\sigma_{1}$. Dashed yellow lines indicate the boundaries between the damaged fabric (DF) and the host rock (HR) and also some grain boundaries in (a). Black squares in (f) are missing pictures. 


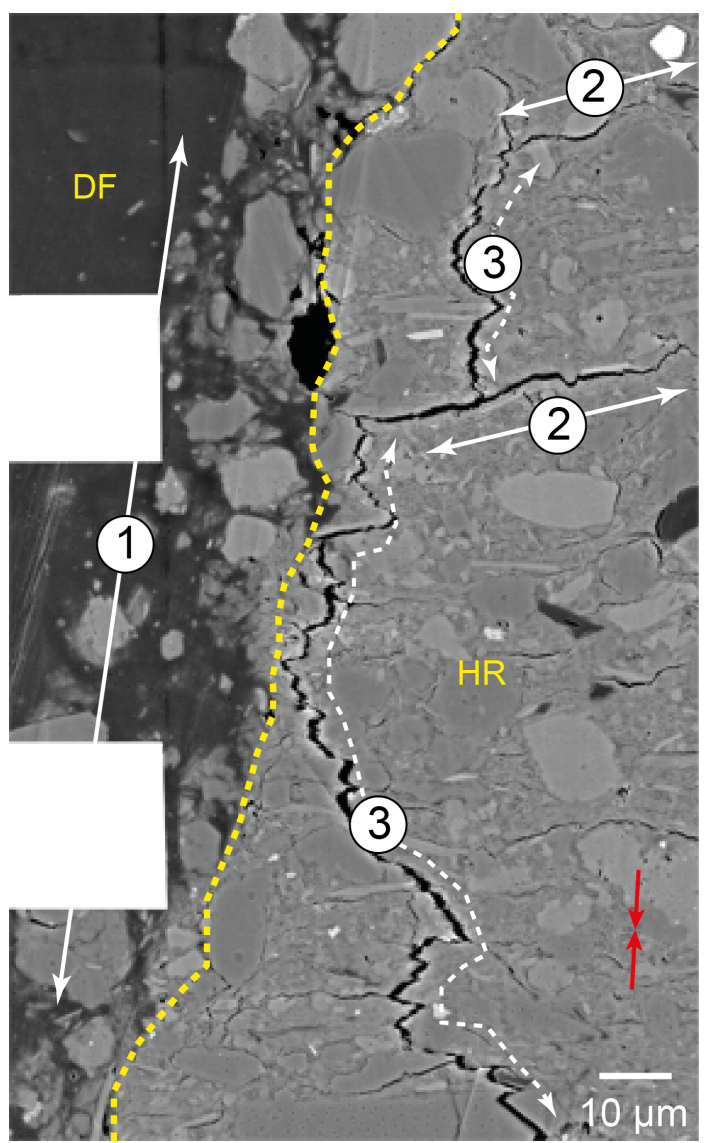

Figure 8. Detailed microstructure close the main fracture (indicated by number 1) in sample COX-2MPa. The main fracture displays internal damaged fabric made of fragments of broken non-clay minerals and clay matrix. Close to the main synthetic fracture, the host rock displays jagged joints subparallel to the main synthetic fracture (indicated by number 3 ) starting and ending at the antithetic fracture (indicated by number 2 ). In all micrographs, the orientation of the principal stress $\left(\sigma_{1}\right)$ is indicated by red arrows. The bedding is perpendicular to $\sigma_{1}$. The dashed yellow line indicates the boundary between the damaged fabric (DF) and the host rock (HR).

in the damaged zone show transgranular fractures (Figs. 9c and 11a). In parts of the damage zone, dilatancy and a strong increase in connected porosity (ROI-4_COX-2MPa, Fig. 8) are indicated by epoxy impregnation. In other parts, (ROI1_COX-10MPa, Figs. 9 and 10) strongly reworked clay matrix is not impregnated and shows no pores visible at the resolution of image ( $83.8 \mathrm{~nm}$ pixel size in Fig. 10b, c).

For COX-2MPa, the DIC analysis shows that the conjugated synthetic fractures form a complex network of fracture branches in the region where they both intersect (Fig. 2c). The ROI-3_COX-2MPa subsample (Fig. 2d) covers two of these branches. Microstructural analysis of these two branches in ROI-3_COX-2MPa shows similar microstructures, with only the fracture apertures being different (Fig. 5c).

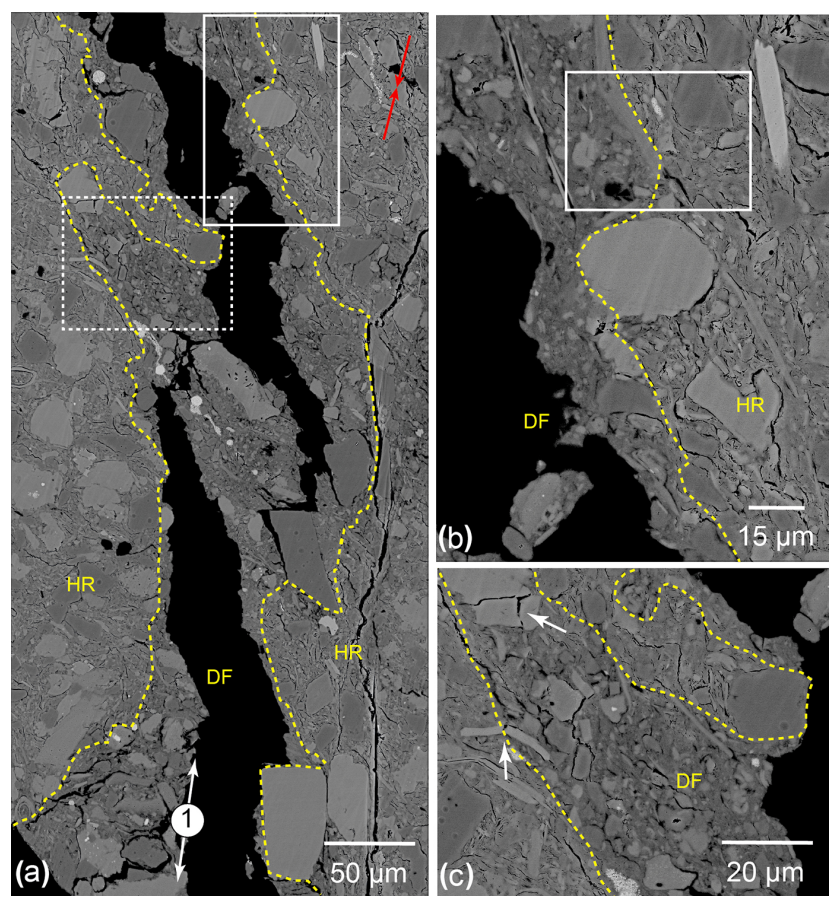

Figure 9. Microstructures of ROI-1 in sample COX-10MPa. (ac) The damaged fabric (DF) within the main fracture (1) is made of fragments of non-clay minerals derived from the dense, tight clay matrix. (a) The large open fracture in the middle of the main fracture (black) is interpreted to develop after the experiment by unloading and/or drying (see Sect. 5.1 for details). In (a) the white box in dashed lines refers to (c), whereas the one in solid lines refers to (b). (b) Details of difference in mineral fabric between DF and the host rock (HR). The white box refers to Fig. 10. (c) Some grains within the damaged fabric, but close to the boundary between the damaged fabric and the host rock, show transgranular fracturing (white arrows). In all micrographs, the orientation of the principal stress $\left(\sigma_{1}\right)$ is indicated by red arrows. The bedding is perpendicular to $\sigma_{1}$. The dashed yellow lines indicate the boundaries between DF and HR.

In both COX-2MPa and COX-10MPa, the damage zone of the synthetic fractures contains an open fracture (Figs. 8, 9 and 11), with apertures of 50-70 $\mu \mathrm{m}$. These large open fractures are filled with epoxy, have matching boundaries and never crosscut the non-clay minerals in the damage zone. Similar fractures are found in COX-2MPa but parallel to the antithetic fractures, with jagged morphologies and matching walls never crossing the non-clay minerals (Fig. 7b, c, e). These fractures are not resolved by DIC at the resolution of the X-ray images and at the strain gage length used in this contribution. 


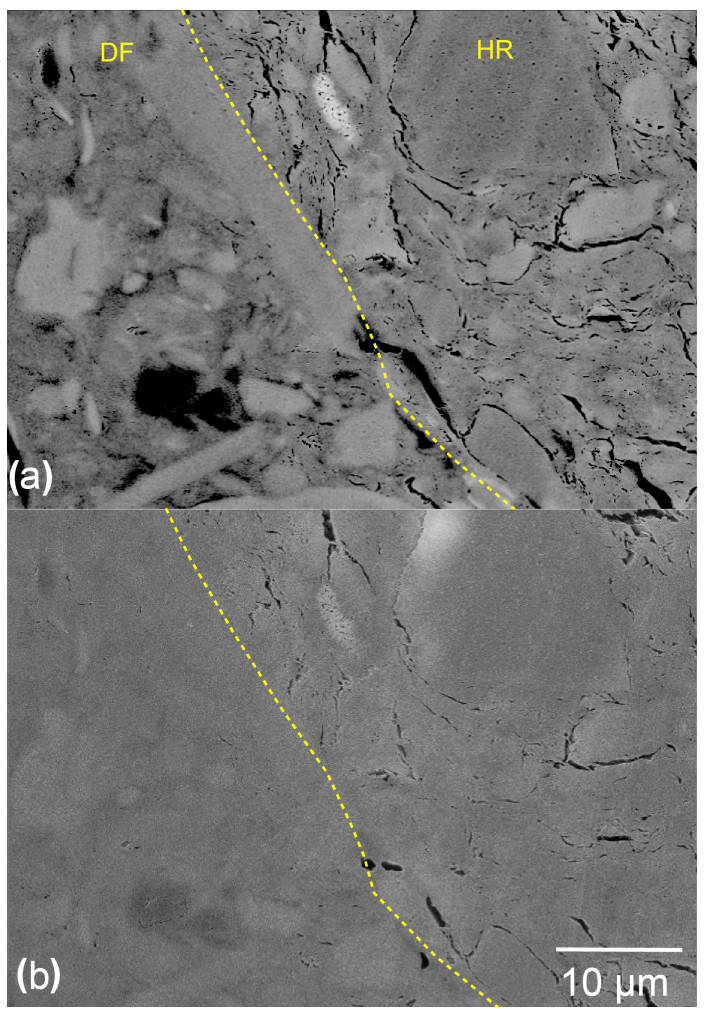

Figure 10. Details of Fig. 9b. Microstructures (ROI-1_COX$10 \mathrm{MPa}$ ) showing details of porosity in BSE-SEM micrograph (a) and SE2 SEM micrograph (b). At the resolution of the SEM micrograph, the damaged fabric appears to be very low porous in comparison to the host rock. The dashed yellow line indicates the boundary between the damaged fabric (DF) and the host rock (HR).

\section{Discussion}

\subsection{Artefacts caused by drying and unloading}

Claystones are sensitive to changes in hydric conditions that can lead to the shrinkage or the swelling of the clay matrix (Galle, 2001; Kang et al., 2003; Soe et al., 2007; GascBarbier and Tessier, 2007; Cosenza et al., 2007; Pineda et al., 2010; Hedan et al., 2012; Renard, 2012; Wang et al., 2013, 2015; Desbois et al., 2014).

The DIC analysis is not affected by this because the images were acquired during deformation of preserved (wet) samples. SEM analysis is done on samples that have been deformed and unloaded, followed by slow drying in a low vacuum and further dehydration in the high vacuum of the BIB and SEM. In COX-10MPa, this is illustrated by Fig. 3c and $\mathrm{d}$. Figure $3 \mathrm{c}$ shows the sample at the end of the deformation experiment, whereas Fig. $3 d$ shows the same sample but about 10 years later, both X-ray imaged. The comparison of Fig. $3 \mathrm{c}$ and $\mathrm{d}$ shows that cracks developed parallel to the bedding and that the apertures of fractures developed during the deformation became larger. These are interpreted to result

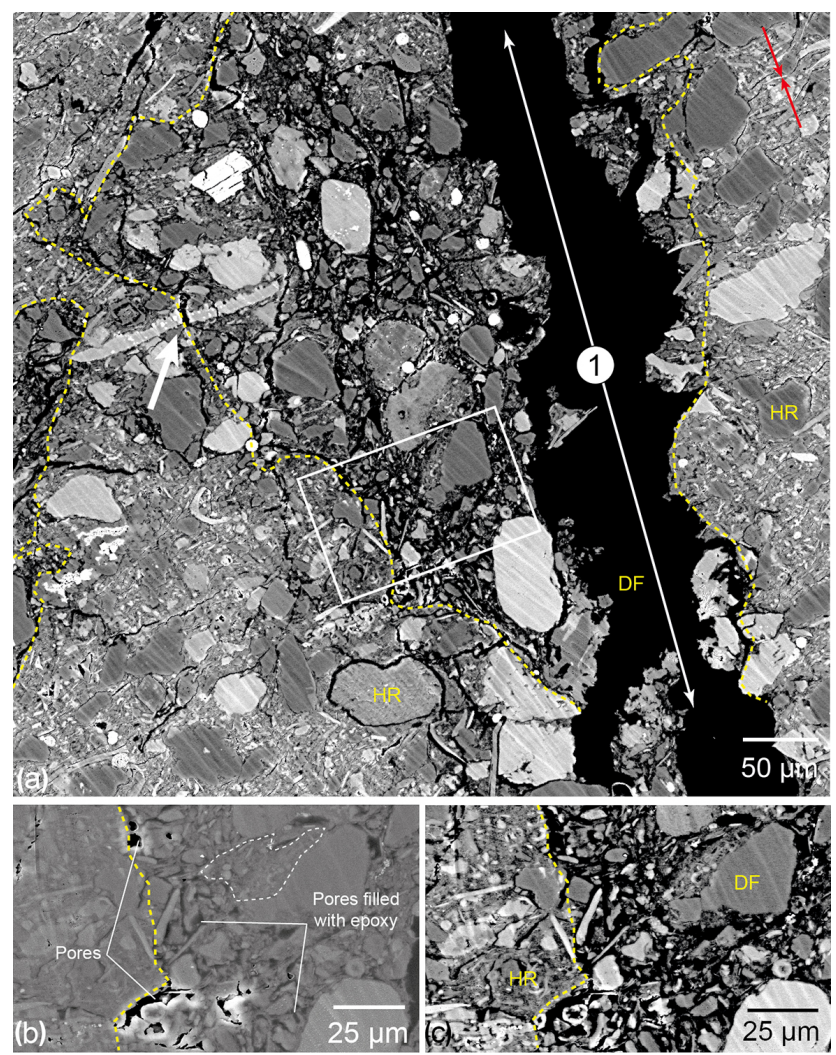

Figure 11. Detailed microstructures at ROI-2 in sample COX10MPa. (a-c) The damaged fabric (DF) within the main synthetic fracture (indicated by number 1) is made of fragments of non-clay minerals and clay matrix derived from the host rock (HR). (a) Some grains within the damaged fabric, but close to the boundary between the damaged fabric and the host rock, show transgranular fracturing (white arrow). The white box refers to Fig. 11a and b. Detailed observations in (b) and c (SE2 SEM and BSE-SEM micrographs of the same sub-area, respectively) show that parts of the damaged fabric display (i) porous island, where pores are between the fragments of non-clay and clay matrix, whereas other parts display (2) low porous islands made of fragments of non-clay minerals embedded in a dense, tight clay matrix (within the region bounded by the dashed white line). Pores within the porous island can either be filled with epoxy (in deep black pixel values) or not. The orientation of the principal stress $\left(\sigma_{1}\right)$ is indicated by red arrows. The bedding is perpendicular to $\sigma_{1}$. The dashed yellow lines indicate the boundaries between the damaged fabric and the host rock.

from unloading and shrinkage during drying of specimens. Though the second sample was not scanned with X-ray in the dry condition, we infer that similar changes also occurred in COX-2MPa: by analogy, there is no reason that the clay matrix in COX-2MPa behaves differently that in COX-10MPa.

The considerations above indicate that some fractures developed during deformation but drying damage overprinted them. Unfortunately, BIB-SEM images (performed on dried samples) do not provide direct information to distinguish if the visible fractures and cracks developed during deforma- 
tion (and subsequently overprinted by drying) or only by drying. However, as presented in the following paragraphs, indirect evidence suggests that the fractures in the fragments between the arrays of antithetic fractures and the antithetic fractures of Type I and Type II developed during deformation.

The fractures in the fragments between the arrays of antithetic fractures (Fig. 7b, c, d) are not present in the low-strain ROI-1_COX-2MPa, and they are subparallel to $\sigma_{1}$ and crosscut the bedding, suggesting strongly that they are formed by experimental deformation.

Antithetic fractures of Type II (Figs. 5, 6 and 7e-i) are interpreted to develop during deformation because (i) the internal microstructures and fabrics are damaged and (ii) DIC recorded a clear localisation of strain in these. Though the antithetic fractures of Type I are not clearly recognised at the resolution of DIC, most of these in COX-2MPa (Fig. 7a) are interpreted to develop during deformation because they are oblique to the bedding and parallel to the antithetic fractures of Type II (Figs. 5, 6 and 7f-g). One exception is the antithetic fractures of Type I observed in ROI-1_COX-10MPa (Fig. 5e), which are parallel to bedding. Mode I fractures subparallel to the main synthetic fractures are less easy to interpret: they may be related to the rotation of blocks between the antithetic fractures (Kim et al., 2004). Cryogenic techniques to preserve wet fabrics combined with ion beam milling and cryo-SEM (Desbois et al., 2008, 2009, 2013, 2014) are the dedicated techniques for addressing this question in the future.

\subsection{Deformation mechanisms}

In our experiments, differential stresses exceed the confining pressure by a factor of $3-15$, which would suggest that dilatant fracturing prevails over other mechanisms (e.g. Kohlstedt et al., 1995). This is partly corroborated from the stress-strain measurements that show major stress drops after peaks of stress (Figs. 2 and 3). In agreement with this, at micro-scale the first conclusion based on the microstructural observations above is the dominantly cataclastic deformation in Callovo-Oxfordian Clay at confining pressures up to $10 \mathrm{MPa}$. Microfracturing, which produces fragments at a range of scales and reworks them into a phyllosilicate-rich cataclastic gouge during frictional flow, is the main process in both samples. This is accompanied by dilatancy and by microfracturing of the original fabric but also by progressive decrease in porosity and pore size in the gouge with the nonclay particles embedded in reworked clay. The structure of macro-scale fracture in the samples compares well with Ishii et al. $(2011,2016)$.

Although in many cases the initial fractures propagate around the hard non-clay grains, there is also significant fracturing of the hard non-clay minerals (e.g. Fig. 7b-d). This can be due to local stress concentrations at contacts between adjacent non-clay minerals or because the clay matrix is so strongly cemented that it can transmit stresses sufficient to fracture calcite and quartz grains. Broken non-clay minerals can displace or rotate with respect to each other (Fig. 7d) with local dilatancy during deformation (Fig. 2b), in agreement with the interpretation of DIC measurements in Bésuelle and Hall (2011) and Lenoir et al. (2007).

In COX-2MPa, the propagation of antithetic fractures of Type I (Fig. 7a) is predominantly in the clay matrix. This is in agreement with the smaller strain in comparison to antithetic fractures of Type II. Antithetic fractures of Type II contain angular non-clay grains with smaller size than those in the host rock. We interpret these as evidence for comminution by grain fracturing. Matching broken grains (Fig. 7e) are rare and in agreement with high-strain cataclastic flow. Fragments of clay aggregates in the antithetic fractures of Type II are much less coherent (Fig. 7h) and more porous than the undeformed COX (Fig. 7i), indicating strong remolding by cataclastic flow and perhaps also plastic deformation of phyllosilicates. Here, because pore morphologies do not show typical shapes that originate from drying, we interpret this to mean that these developed during deformation.

Microstructures in the main synthetic fractures, both in COX-2MPa (Fig. 8) and COX-10 MPa (Figs. 9 and 11), are similar. Angular non-clay minerals in the reworked clay matrix have a wide range of grain sizes, smaller than those in the host rock. These characteristics are typical for cataclasis (Passchier and Trouw, 2005). In COX-2MPa, the cataclastic gouge seems to be more porous than in COX-10 MPa; this is as expected for the lower mean stress, but firm conclusions require further study to exclude that this is an unloading and drying effect. For COX-10MPa, the porosity in the clay matrix is clearly reduced in comparison to the one in the host rock: most pores, if present, are below the resolution of SEM (Figs. 9 and 10). The mechanism of this compaction during shearing is interpreted to be a combination of cataclasis of the cemented clay matrix and shear-induced rearrangement of clay particles around the fragments of non-clay particles.

\subsection{Conceptual model of microstructure development in triaxially deformed COX}

Based on BIB-SEM microstructural observations, we propose the following sequence of micromechanisms in the Callovo-Oxfordian Clay (Fig. 12):

\section{(1) \& (2) Microfracturing}

Incipient deformation occurs by intergranular microfractures propagating in the clay matrix and transgranular and intragranular microfractures propagating in non-clay minerals, both resulting in the fragmentation of the original fabric and in agreement with the high compressive strength of this cemented mudstone. Intergranular microfractures are interpreted to be initiated from pores, propagating along weak contacts at non-clay mineral-clay matrix interfaces or along 

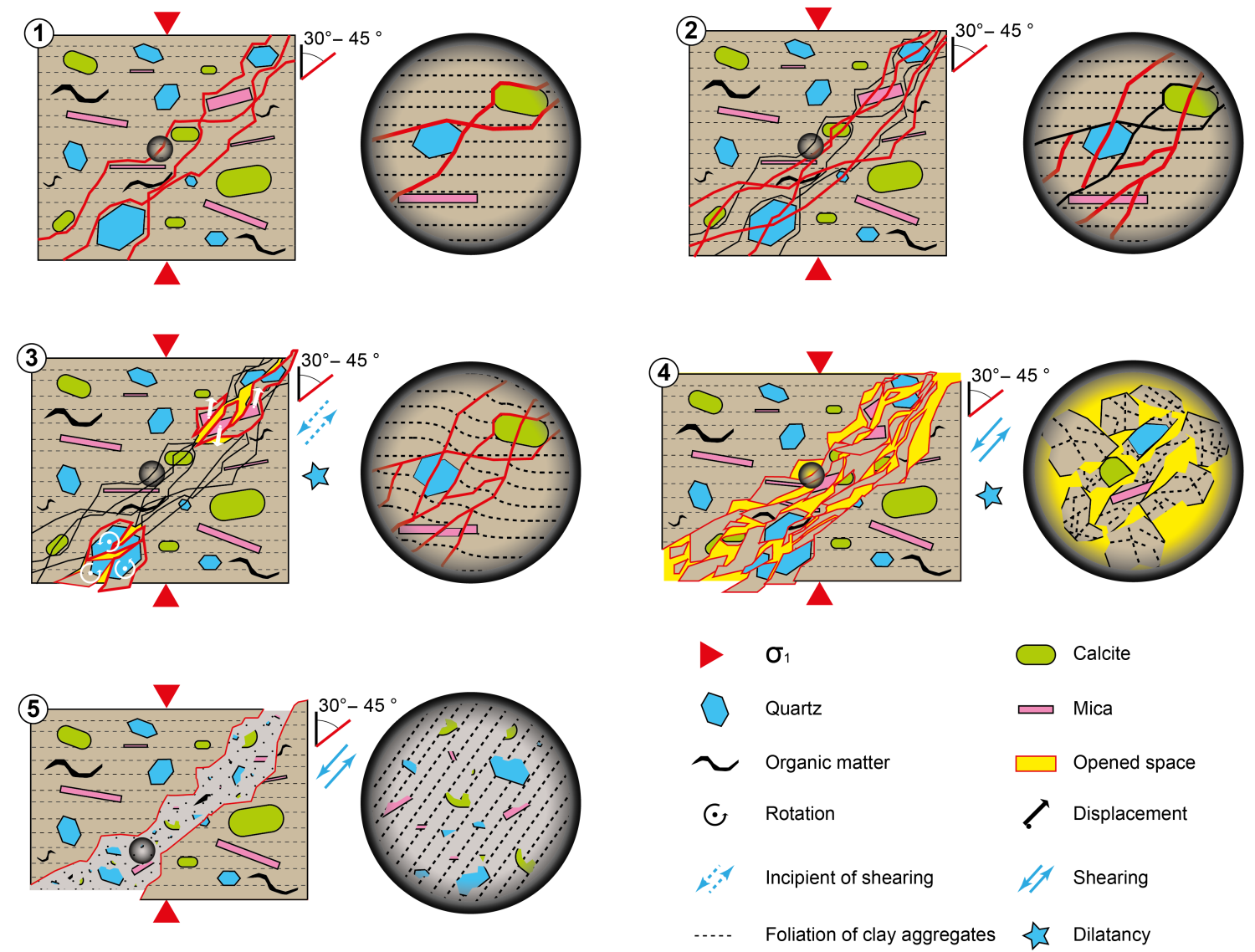

Figure 12. Conceptual model of microstructure development in triaxially deformed COX. (1) and (2) show microfracturing. In (1) intergranular microcracking initiating at non-clay minerals and clay minerals (NCM-CM) interfaces and propagating within $\mathrm{CM}$. In (2) fragmentation of original fabric by transgranular and intragranular microfracturing of NCM. $(3,4)$ Cataclastic shearing with plasticity of phyllosilicates, macroscopic failure. In (3) incipient of shearing enhanced by plasticity of phyllosilicates at microfracture boundaries initiates cataclastic flow of original fabric's fragments. In (4) ongoing shearing drives cataclastic flow, and reworking of CM in original fabric's fragments. (5) Resealing of the damage zone by shear and pore collapse, evolution of clay gouge. See text for details. CM: clay matrix; NCM: non-clay minerals.

(001) cleavage planes of phyllosilicates (Chiarelli et al., 2000; Klinkenberg et al., 2009; Den Hartog and Spiers, 2014, Jessel et al., 2009). Note here that probably the biggest unknown at present in the micromechanisms of deformation in claystones is the nature of cement bonds between grains; further work in this project is aimed at understanding this better.

\section{( 3 \& 4) Cataclastic shearing with plasticity of phyllosilicates, macroscopic failure}

Further deformation occurs by frictional sliding affecting the process zone at microfracture boundaries and in relays between fractures. Mechanisms are abrasion and bending of phyllosilicates by cataclastic and crystal plastic mechanisms. This is accompanied by rotation of fragments and cataclastic flow. This stage is interpreted to start at the peak stress in the stress-strain curve, accompanied by local dilatancy. At the specimen scale, fractures link up, resulting in loss of cohe- sion. In restraining sections along the fractures, reworking of the clay matrix reduces porosity and eliminates large pores, changing the pore size distributions. The specimen suffers from a major loss of cohesion accompanied by dilatancy and stress drop after peak stress.

\section{(5) Resealing of the damage zone by shear and pore collapse, evolution of clay gouge}

Ongoing abrasion of the fragments and comminution develop a cataclastic fabric. A full understanding of the deformation mechanisms in cataclastic clay aggregates requires more work, but the grain sliding (Chiarelli et al., 2000) and grain rotation between low-friction clay particles together with collapsing of porosity is inferred because (i) slip on the (001) basal planes of clay particles is much easier than shearing related to grain breakage (see Haines et al., 2013 and Crider, 2015) and (ii) residual strength observed after spec- 
imen failure argues for sliding between low frictional clay particles (Lupini et al., 1981). At sufficiently high strain, this stage would correspond to the residual strength, resulting in the resealing of initial fracture porosity by filling the fractures with clay gouge. In this stage, cataclasis of non-clay particles is expected to become less important because they are embedded in reworked clay.

The conceptual model above for microstructure evolution in triaxially deformed COX is a first look based on direct grain-scale observation of microstructures. Our ongoing studies focus on the nature of the cement and microstructures of the damage zone at fracture tips to better understand the localisation mechanisms.

\section{Conclusions}

The integration of bulk stress-strain data and the analysis of displacement fields by 3-D and 2-D digital image correlation (DIC) with broad ion beam cutting and scanning electron microscopy (BIB-SEM) is a powerful multi-scale method to study the deformation behaviour of mudstones.

We studied samples of Callovo-Oxfordian Clay (COX) subjected to triaxial compression at 2 and $10 \mathrm{MPa}$ confining pressure. DIC was used to locate regions deformed to different states of strain and BIB-SEM allows microstructural investigations of mineral and porosity fabrics down to the nanometre scale.

Microstructures show evidence for dominantly cataclastic mechanisms (intergranular, transgranular, intragranular cracking, grain rotation, clay particle bending) down to the nanometre scale.

At low strain, the dilatant fabric contains individually recognisable open fractures, while at high strain in shear fractures the reworked clay gouge evolves towards smaller pores than the undeformed material and corresponding resealing of initial fracture porosity. This shear-induced resealing is more important at the higher confining pressure.

This study provides a first step towards a microphysical basis for constitutive models of deformation and fluid flow in cemented mudstones, with an improved extrapolation of these models for long timescales.

In the future, the microstructures in experimentally deformed specimens need to be compared with the microstructures in naturally deformed claystones (Laurich et al., 2014) in order to help extrapolate the constitutive models to long timescales.

\section{Data availability}

This publication is based on deformation experiments performed by Lenoir et al. (2007) and Besuelle and Hall (2011). These papers are mentioned in the manuscript and available on the journal websites.
Competing interests. The authors declare that they have no conflict of interest.

Acknowledgements. We thank ANDRA for providing samples. We are very grateful to the reviewers G. Dresen and A. Dimanov for their constructive and valuable comments.

Edited by: R. Heilbronner

Reviewed by: G. Dresen and A. Dimanov

\section{References}

Andò, E., Hall, S. A., Viggiani, G., Desrues, J., and Besuelle, P.: Grain-scale experimental investigation of localised deformation in sand: a discrete particle tracking approach, Acta Geotechnica, 7, 1-13, 2012.

ANDRA: Evaluation of the feasibility of a geological repository in an argillaceous formation, Meuse/Haute Marne site, Dossier 2005, Argiles, Report Series, ANDRA, 2005.

Bauer-Plaindoux, C., Tessier, D., and Ghoreychi, M.: Propriétés mécaniques des roches argileuses carbonateés: importance de la relation calcite-argile, C. R. Acad. Sci. Paris, Sciences de la Terre et des planètes, Earth Planet. Sci., 326, 231-237, 1998.

Bernier F., Li, X. L., Bastien,s W., Ortiz, L., Van Geet, M., Wouters, L., Frieg, B., Blümling, P., Desrues, J., Viaggiani, G., Coll, C., Chancole, S., De greef, V., Hamza, R., Malinsky, L., Vervoort, A., Vanbrabant, Y., Debeker, B., Verstraelen, J., Govaerts, A., Wevers, M., Labiouse, V., Escoffier, S. Mathier, J.-F., Gastaldo, L., and Bühler, C.: Fractures and Self-healing within the Excavation Disturbed Zone in Clays (SELFRAC), Final report, European Commission, CORDIS Web Site, EUR 22585, 56 pp., 2007.

Bésuelle, P. and Hall, S. A.: Characterization of the Strain Localization in a Porous Rock in Plane Strain Condition Using a New True-Triaxial Apparatus, Advances in bifurcation and degradation in geomaterials, Springer Series in geomechanics and geoengineering, 11, 345-352, 2011.

Boisson, J. Y.: Clay Club Catalogue of Characteristics of Argillaceous Rocks, OECD/NEA/RWMC/IGSC (Working Group on measurement and Physical understanding of Groundwater flow through argillaceous media) august 2005 Report NEA no. 4436 (Brochure and CD-Rom including data base), OECD/NEA Paris, France, 72 pp., 2005.

Bonin, B.: Deep geological disposal in argillaceous formations: studies at the tournemire test site, J. Contam. Hydrogeol., 35, 315-330, 1998.

Bornert, M., Vales, F., Gharbi, H., and Nguyen Minh, D.: Multiscale full-field strain measurements for micromechanical investigations of the hydromechanical behaviour of clayey rocks, Strain, 46, 33-46, 2010.

Bos, B. and Spiers, C. J.: Experimental investigation into the microstructural and mechanical evolution of phyllosilicate-bearing fault rock under conditions favouring pressure solution, J. Struct. Geol., 23, 1187-1202, 2001.

Bourcier, M., Dimanov, A., Héripré, E., Raphanel, J. L., Bornert, M., and Desbois, G.: Full field investigation of salt deformation at room temperature: cooperation of crystal plasticity and grain sliding, in: mechanical behavior of salt VII, Berest, edited by: 
Ghoreychi, M., Hadj-Hassen, F., and Tijani, M., Taylor \& Francis group, London, 37-43, 2012.

Bourcier, M., Bornert, M, Dimanov, A., heripré, E., and Raphanel, J. L.: Multiscale experimental investigation of crystal plasticity and grain boundary sliding in synthetic halite using digital image correlation, J. Geophys. Res.-Sol. Ea., 118, 511-526, 2013.

Chiarelli, A. S., Ledesert, B., Sibal, M., Karami, M., and Hoteit, N.: Influence of mineralogy and moisture content on plasticity and induced anisotropic damage of a claystone: application to nuclear waste disposal, Bull. Soc. Géol. France, 171, 621-627, 2000.

Chiarelli, A. S., Shao, J. F., and Hoteit, N.: Modeling of elastoplastic damage behavior of a claystone, Int. J. Plasticity, 19, 23-45, 2003.

Collettini, C., Niemeijer, A., Viti, C., and Marone, C.: Fault zone fabric and fault weakness, Nature, 462, 907-910, 2009.

Cosenza, P., Ghorbani, A., Florsch, N., and Revil, A.: Effects of Drying on the Low-Frequency Electrical Properties of Tournemire Argillites, Pure Appl. Geophys., 164, 2043-2066, 2007.

Crider, J. G.: The initiation of brittle faults in crystalline rock, J. Struct. Geol., 77, 159-174, 2015.

Curtis, M. E., Ambrose, R. J., Sondergeld, C. H., and Rai, C. S.: Structural Characterization of Gas Shales on the Micro- and Nano-Scales, Canadian Unconventional Resources and International Petroleum Conference, Society of Petroleum Engineers, Calgary, Alberta, Canada, 15 pp., 2010.

Dautriat, J., Bornert, M., Gland, N., Dimanov, A., and Raphanel, J.: Localized deformation induced by heterogeneities in porous carbonate analysed by multi-scale digital image correlation, Tectonophysics, 503, 100-116, 2011.

Dehandschutter, B., Vandycke, S., Sintubin, M., Vandenberghe, N., Gaviglio, P., Sizun, J.-P., and Wouters, L.: Microfabric of fractured Boom Clay at depth: a case study of brittle-ductile transitional clay behaviour, Appl. Clay Sci., 26, 389-401, 2004.

Den Hartog, S. A. M. and Spiers, C.: A microphysical model for fault gouge friction applied to subduction megathrusts, J. Geophys. Res., 119, 1510-1529, 2014.

Desbois, G., Urai, J. L., Burkhardt, C., Drury, M. R., Hayles, M., and Humbel, B.: Cryogenic vitrification and 3-D serial sectioning using high resolution cryo-FIB SEM technology for brine-filled grain boundaries in halite: first results, Geofluids, 8, 60-72, 2008.

Desbois, G., Urai, J. L., and Kukla, P. A.: Morphology of the pore space in claystones - evidence from BIB/FIB ion beam sectioning and cryo-SEM observations, E-Earth, 4, 15-22, 2009.

Desbois, G., Urai, J. L., Kukla, P. A., Konstanty, J., and Baerle, C.: High-resolution 3-D fabric and porosity model in a tight gas sandstone reservoir: a new approach to investigate microstructures from mm- to nm-scale combining argon beam crosssectioning and SEM imaging, J. Petrol. Sci. Eng., 78, 243-257, 2011.

Desbois G., Urai, J. L., Pérez-Willard, F., Radi, Z., van Offern, S., Burkart, I., Kukla, P. A., and Wollenberg, U.: Argon broad ion beam tomography in cryogenic scanning electron microscope: a novel tool for the investigation of preserved representative microstructures, Application to rock salt and other sedimentary rocks, J. Microsc.-Oxford, 249, 215-235, 2013.

Desbois, G., Urai, J. L., Hemes, S., Brassinnes, S., De Craen, M., and Sillen, X.: Nanometer-scale pore fluid distribution and dry- ing damage in preserved clay cores from Belgian clay formations inferred by BIB-cryo-SEM, Eng. Geol., 170, 117-131, 2014.

Desbois, G., Urai, J. L, Hemes, S., Schröppel, B., Schwarz, J.O., Mac, M., and Weiel, D.: Multiscale analysis of porosity in diagenetically altered reservoir sandstone from the Permian Rotliegend (Germany), J. Petrol. Sci. Eng., 140, 128-148, 2016.

Evans, B. and Wong, T.-F.: Fault mechanics and transport properties of rocks, Academic Press, International Geophysics, 51, 524 pp., 1992.

Fabre, G. and Pellet, F.: Creep and time-dependent damage in argillaceous rocks, Int. J. Rock Mech. Min., 43, 950-960, 2006.

Fauchille, A.-L., Hedan, S., Prêt, D., Cosenza, P., Valle, V., and Cabrera, J.: Relationships between desiccation cracking behavior and microstructure of the Tournemire clay-rock by coupling DIC and SEM methods, in: Geomechanics from micro to macro, edited by: Soga, K., Kumar, K., Biscontin, G., and Kuo, M., 1421-1424, 2015.

Faulkner, D. R., Lewis, A. C., and Rutter, E. H.: On the internal structure and mechanics of large strike-slip fault zones: field observations of the Carboneras fault in southeastern Spain, Tectonophysics, 367, 235-251, 2003.

Fouché, O., Wright, H., Le Cléac'h, J.-M., and Pellenard, P.: Fabric control on strain and rupture of heterogeneous shale samples by using a non-conventional mechanical test, Appl. Clay Sci., 26, 367-387, 2004.

French, M. E., Chester, F. M., and Schester, J. S.: Micromechanisms of creep in clay-rich gouge from the Central Deforming Zone of the San Andreas Fault, J. Geophys. Res.-Sol. Ea., 120, 827-849, 2015.

Galle, C.: Effect of drying on cement-based materials pore structure as identified by mercury intrusion porosimetry: A comparative study between oven-, vacuum-, and freeze-drying, Cement Concrete Res., 31, 1467-1477, 2001.

Gasc-Barbier, M. and Tessier, D.: Structural Modifications of a Hard Deep Clayey Rock due to Hygro-Mechanical Solicitations, Int. J. Geomech., 7, 227-235, 2007.

Gasc-Barbier, M., Chanchole, S., and Bérest, P.: Creep behavior of Bure clayey rock, Appl. Clay Sci., 26, 449-458, 2004.

Gaucher, E., Robelin, C., Matray, J. M., Negrel, G., Gros, Y., Heitz, J. F., Vinsot, A., Rebours, H., Cassagnabere, A., and Bouchet, A.: ANDRA underground research laboratory: interpretation of the mineralogical and geochemical data acquired in the Callovian-oxfordian Formation by investigative drilling, Phys. Chem. Earth, 29, 55-77, 2004.

Gratier, J. P., Jenatton, L., Tisserand, D., and Guiguet, R. Indenter studies of the swelling, creep and pressure solution of Bure argillite, Appl. Clay Sci., 26, 459-472, 2004.

Haines, S. H., Van der Pluijm, B., Ikari, M. J., Saffer, D. M., and Marone, C.: Clay fabric intensity in natural and artificial fault gouges: Implications for brittle fault zone processes and sedimentary basin clay fabric evolution, J. Geophys. Res., 114, B05406, doi:10.1029/2008JB005866, 2009.

Haines, S. H., Kaproth, B., Marone, C., Saffer, D., and Van der Pluijm, B.: Shear zones in clay-rich fault gouge: A laboratory study of fabric development and evolution, J. Struct. Geol., 51, 206-225, 2013.

Hall, S., Bornert, M., Desrues, J., Pannier, Y., Lenoir, N., Viggiani, G., and Bésuelle, P.: Discrete and Continuum analysis of lo- 
calised deformation in sand using X-ray CT and Volumetric Digital Image Correlation, Géotechnique, 60, 315-322, 2010.

Heath, J. E., Dewers, T. A., McPherson, B. J. O. L., Petrusak, R., Chidsey, T. C., Rinehart, A. J., and Mozley, P. S.: Pore networks in continental and marine mudstones: Characteristics and controls on sealing behavior, Geosphere, 7, 429-454, 2011.

Hedan, S., Cozensa, P., Valle, V., Dudoignon, P., Fauchille, A.-L., and Cabrera, J.: Investigation of the damage induced by desiccation and heating of Tournemire argillite using digital image correlation, Int. J. Rock Mech. Min., 51, 64-75, 2012.

Hemes, S., Desbois, G., Urai, J. L., De Craen, M., and Honty, M.: Variations in the morphology of porosity in the Boom Clay Formation: insights from 2-D high resolution, BIB-SEM imaging and Mercury injection Porosimetry, Neth. J. Geosci., 92, 275300, 2013.

Hemes, S., Desbois, G., Urai, J. L., Schröppel, B., and Schwarz, J.-O.: Multi-scale characterization of porosity in Boom Clay (HADES, Mol, Belgium) using a combination of $\mu$-CT, BIBSEM and serial FIB-SEM techniques, Micropor. Mesopor. Mat., 208, 1-20, 2015.

Holland, M., Urai, J. L., van der Zee, W., Stanjek, H., and Konstanty, J.: Fault gouge evolution in highly overconsolidated claystones, J. Struct. Geol., 28, 323-332, 2006.

Houben, M. A., Desbois, G., and Urai, J. L.: Pore morphology and distribution in the shaly facies of Opalinus clay (Mont Terri, Switzerland): insights from representative 2-D BIB-SEM investigations on mm- to nm- scales, Appl. Clay Sci., 71, 82-97, 2013.

Houben, M. A., Desbois, G., and Urai, J. L.: A comparative study of representative 2-D microstructures in Shaly and Sandy facies of Opalinus Clay (Mont Terri, Switzerland) inferred form BIBSEM and MIP methods, Mar. Petrol. Geol., 49, 143-161, 2014.

IAEA: The safety case and safety assessment for radioactive waste disposal, Draft safety guide, International atomic energy agency, report no. DS 355, Vienna, 2008.

Ingram, G. M. and Urai, J. L.: Top-seal leakage through faults and fractures, the role of mudrock properties, Geol. Soc. Sp., 158, 125-135, 1999.

Ishii, E.: Far-field stress dependency of the failure mode of damagezone fractures in fault zones: Results from laboratory tests and field observations of siliceous mudstone, J. Geophys. Res.-Sol. Ea., 121, 70-91, doi:10.1002/2015JB012238, 2016.

Ishii, E., Sanada, H., Funaki, H., Sugita, Y., and Kurikami, H.: The relationships among brittleness, deformation behavior, and transport properties in mudstones: An example from the Horonobe Underground Research Laboratory, Japan, J. Geophys. Res., 116, B09206, doi:10.1029/2011JB008279, 2011.

Jessell, M. W., Bons, P. D., Griera, A., Evans, L., and Wilson, C. J. L.: A tale of two viscosities, J. Struct. Geol., 31, 719-736, 2009.

Jordan, P. and Nüesch, R.: Deformation behavior of shale interlayers in evaporite detachment horizons, Jura overthrust, Switzerland, J. Struct. Geol., 11, 859-871, 1989.

Kang, M.-S., Watabe, Y., and Tsuchida, T.: Effect of Drying Process on the Evaluation of Microstructure of Clays using Scanning Electron Microscope (SEM) and Mercury Intrusion Porosimetry (MIP), Proceedings of The Thirteenth International Offshore and Polar Engineering Conference Honolulu, Hawaii, USA, 25-30 May, 2003.
Katz, O. and Reches, Z.: Microfracturing, damage, and failure of brittle granites, J. Geophys. Res., 109, B01206, doi:10.1029/2002JB001961, 2004.

Kaufhold, A., Halisch, M., Zacher, G., and Kaufhold, S.: X-ray computed tomography investigation of structures in Opalinus Clay from large-scale to small-scale after mechanical testing, Solid Earth, 7, 1171-1183, doi:10.5194/se-7-1171-2016, 2016.

Keller, L., Schuetz, P., Erni, R., Rossell, M. D., Lucas, F., Gasser, P., and Holzer, L.: Characterization of multi-scale microstructural features in Opalinus Clay, Micropor. Mesopor. Mat., 170, 8394,2013.

Keller, L. M., Holzer, L., Wepf, R., and Gasser, P.: 3-D geometry and topology of pore pathways in Opalinus clay: Implications for mass transport, Appl. Clay Sci., 52, 85-95, 2011.

Kim, Y.-S., Peacock, D. C. P., and Sanderson, D. J.: Fault damage zones, J. Struct. Geol., 26, 503-517, 2004.

Klaver, J., Desbois, G., Urai, J. L., and Littke, R.: BIB-SEM study of porosity of immature Posidonia shale from the Hils area, Germany, Int. J. Coal Geol., 103, 12-25, 2012.

Klaver, J., Desbois, G., Littke, R., and Urai, J. L.: BIB-SEM characterization of pore space morphology and distribution in postmature to overmature samples from the Haynesville and Bossier Shales, Mar. Petrol. Geol., 59, 451-466, 2015.

Klinkenberg, M., Kaufhold, S., Dohrmann, R., and Siegesmund, S.: Influence of carbonate microfabrics on the failure strength of claystones, Eng. Geol., 107, 42-54, 2009.

Kohlstedt, D. L., Evans, B., and Mackwell, S. J.: Strength of the lithosphere: constraints imposed by laboratory experiments, J. Geophys. Res., 100, 17587-17602, 1995.

Laurich, B., Urai, J. L., Desbois, G., Vollmer, C., and Nussbaum, C.: Microstructural evolution of an incipient fault zone in Opalinus Clay: Insights from an optical and electron microscopic study of ion-beam polished samples from the Main Fault in the Mont Terri underground research laboratory, J. Struct. Geol., 67, 107128, 2014.

Laurich, B., Urai, J. L., and Nussbaum, C.: Microstructures and deformation mechanisms in Opalinus Clay: insights from scaly clay from the Main Fault in the Mont Terri Rock Laboratory $(\mathrm{CH})$, Solid Earth, 8, 27-44, doi:10.5194/se-8-27-2017, 2017.

Lee, M. R., Bland, P. A., and Graham, G.: Preparation of TEM samples by focused ion beam (FIB) techniques: applications to the study of clays and phyllosilicates in meteorites, Mineral. Mag., 67, 581-592, 2003.

Lenoir, N., Bornert, M., Desrues, J., Besuelle, P., and Viggiani, G.: Volumetric digital image correlation applied to X-ray microtomography images from triaxial compression tests on argillaceous rock, Strain, 43, 193-205, 2007.

Logan, J. M., Friedman, M., Higgs, N., Dengo, C., and Shimamoto, T.: Experimental studies of simulated gouge and their application to studies of natural fault zones, in: Proceedings of Conference VIII on Analysis of Actual Fault Zones in Bedrock, US Geological Survey, Open File Report, 79-1239, 1979.

Logan, J. M., Dengo, C. A., Higgs, N. G., and Wang, Z. Z.: Fabrics of Experimental Fault Zones: Their Development and Relationship to Mechanical Behavior, in: Fault Mechanics and Transport Properties of Rocks - A Festschrift in Honor of W. F. Brace, edited by: Evans, B. and Wong, T., Academic Press, 33-67, 1992. 
Logan, J. M. and Rauenzahn, K. A.: Frictional dependence of gouge mixtures of quartz and montmorillonite on velocity, composition and fabric, Tectonophysics, 144, 87-108, 1987.

Loucks, R. G., Reed, R. M., Ruppel, S. C., and Jarvie, D. M.: Morphology, Genesis, and Distribution of Nanometer-Scale Pores in Siliceous Mudstones of the Mississippian Barnett Shale, J. Sediment. Res., 79, 848-861, 2009.

Lupini, J. F., Skinner, A. E., and Vaughan, P. R.: The drained residual strength of cohesive soils, Géotechnique 31, 181-213, 1981.

Marone, C. and Scholz, C. H.: Particle-size distribution and microstructures within simulated fault gouge, J. Struct. Geol., 11, 799-814, 1989.

Milliken, K. L., Rudnicki, M., Awwiller, D. N., and Zhang, T.: Organic matter-hosted pore system, Marcellus formation (Devonian), Pennsylvania, AAPG bulletin, 97, 177-200, 2013.

Morgenstern, N. R. and Tchalenko, J. S.: Microscopic structures in kaolin subjected to direct shear, Geotechnique, 17, 309-328, 1967.

Nagra: Technischer Bericht 02-03, Projekt Opalinuston, Synthese der geowissenschaftlichen Untersuchungsergebnisse, 2002.

NEA: Post-closure safety case for geological repositories. Nature and purpose, OECD/NEA, no. 3679, Paris, France, 2004.

Neerdael, B. and Boyazis J. P.: The Belgium underground research facility: status on the demonstration issues for radioactive waste disposal in clay, Nucl. Eng. Des., 176, 89-96, 1997.

Niemeijer, A. R. and Spiers, C. J.: Velocity dependence of strength and healing behaviour in simulated phyllosilicate-bearing fault gouge, Tectonophysics, 427, 231-253, 2006.

Nüesch, R.: Das mechanische Verhalten von Opalinuston, PhD Thesis, ETH Zürich, 244 pp., 1991.

ONDRAF/NIRAS: SAFIR 2, Safety Assessment and Feasibility Interim Report 2, NIROND 2001-06, 2001.

Passchier, C. W. and Trouw R. A. J.: Microtectonics, Springer, 366 pp., 2005.

Pineda, J., Romero, E., Gómez, S., and Alonso, E.: Degradation effects at microstructural scale and their consequences on macroscopic behaviour of a slightly weathered siltstone, in: Geomechanics and Geotechnics, From Micro to Macro, Two Volume Set, edited by: Bolton, M., CRC Press 2010, 73-78, 2010.

Renard, F.: Microfracturation in rocks: from microtomography images to processes, Eur. Phys. J. Appl. Phys., 60, 24203, 2012.

Richard, J., Gratier, J. P., Doan, M.-L., Boullier, A.-M., and Renard, F.: Rock and mineral transformations in a fault zone leading to permanent creep: Interactions between brittle and viscous mechanisms in the San Andreas Fault, J. Geophys. Res.-Sol. Ea., 119, 8132-8153, 2015.

Robinet, J. C., Sardini, P., Coelho, D., Parneix, J.-C., Dimitri, P., Sammartino, S., Boller, E., and Altmann, S.: Effects of mineral distribution at mesoscopic scale on solute diffusion in a clay-rich rock: Example of the Callovo-Oxfordian mudstone (Bure, France), Water Resour. Res., 48, W05554, doi:10.1029/2011WR011352, 2012.
Rutter, E. H., Maddock, R. H., Hall, S. H., and White S. H.: Comparative microstructures of natural and experimentally produced clay-bearing fault gouges, Pure Appl. Geophys., 124, 3 30, 1986.

Salters, V. J. M. and Verhoef, P. N. W. (Eds.): Geology and nuclear waste disposal, Geologica Ultraiectina Special Publication, Instituut voor Aardwetenschappen der Rijksuniversiteit te Utrecht, Institute of Earth Sciences, Utrecht, 1, 399 pp., 1980.

Schmatz, J., Berg, S., Urai J., and Ott, H.: Nano-scale imaging of pore-scale fluid-fluid-solid contacts in sandstone, Geophys. Res. Lett., 42, 2189-2195, 2015.

Shapira, J. P.: Long-term waste management: present status and alternatives, Nucl. Instrum. Methods, A280, 568-582, 1989.

Soe, A. K. K., Osada, M., Takahashi, M., and Sasaki, T.: Characterization of drying-induced deformation behaviour of Opalinus Clay and tuff in no-stress regime, Environ. Geol., 58, 1215-1225, 2009.

Sone, H., Morales, L. F., and Dresen, G.: Microscopic observations of shale deformation from in-situ deformation experiments conducted under a scanning electron microscope, ARMA, 15-27, 2015.

Song, Y., Davy, C. A., Bertier, P., and Troadec, D.: Understanding fluid transport through claystones from their 3-D nanoscopic pore network, Micropor. Mesopor. Mat., 228, 64-85, 2016.

Stow, D. A. V.: Fine-grained sediments: Terminology, Q. J. Eng. Geol., 14, 243-244, 1981.

Tchalenko, J. S.: The evolution of kink-bands and the development of compression textures in sheared clays, Tectonophysics, 6, 159-174, 1968.

Wang, L. L., Bornert, M., Chancole, S., Yang, S., Heripré, E., Tanguy, A., and Caldemaison, D.: Micro-scale experimental investigation of the swelling anisotropy of the Callovo- Oxfordian argillaceous rock, Clay Miner., 48, 391-402, 2013.

Wang, L. L., Bornert, M., Chancole, S., Heripré, E., and Yang, S.: Micromechanical experimental investigation of mudstones, Géotechnique letters, 4, 306-309, 2015.

Warr, L. N., Wojatschke, J., Carpenter, B. M., Marone, C., Schleicher, A. M., and van der Pluijm, B. A.: A "slice-and-view" (FIBSEM) study of clay gouge from the SAFOD creeping section of the San AndreasFault at $2.7 \mathrm{~km}$ depth, J. Struct. Geol., 69, 234244, 2014.

Yang, D. S., Bornert, M., Chanchole, S., Gharbi, H., Valli, P., and Gatmiri, B.: Dependence of elastic properties of argillaceous rocks on moisture content investigated with optical full-field strain measurement techniques, Int. J. Rock Mech. Min., 53, 4555, 2012. 